\title{
Effect of the COVID-19 pandemic on dental interns in Saudi Arabia
}

\author{
Syed Fareed Mohsin ${ }^{\mathrm{a}, 1}$, Shahzad Ali Shah ${ }^{\mathrm{b}, 2}$, Muhammad Atif Saleem Agwan ${ }^{\mathrm{b}, *}$, Saqib Ali ${ }^{\mathrm{c}, 3}$, \\ Ziyad Ahmad Alsuwaydani ${ }^{\mathrm{d}, 4}$ and Saleh Ahmad AlSuwaydani ${ }^{\mathrm{e}}$

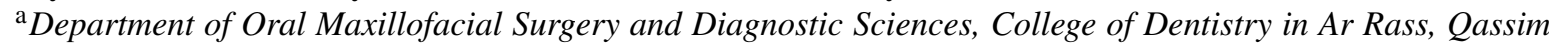 \\ University, Ar Rass, Kingdom of Saudi Arabia \\ ${ }^{\mathrm{b}}$ Department of Restorative Dentistry, College of Dentistry in Ar Rass, Qassim University, Ar Rass, Kingdom of \\ Saudi Arabia \\ ${ }^{\mathrm{c}}$ Department of Biomedical Dental Sciences, College of Dentistry, Imam Abdulrahman Bin Faisal University, \\ Dammam, Kingdom of Saudi Arabia \\ ${ }^{\mathrm{d}}$ College of Dentistry in Ar Rass, Qassim University, Ar Rass, Kingdom of Saudi Arabia \\ ${ }^{\mathrm{e}}$ Unaizah College of Medicine, Qassim University, Unaizah, Kingdom of Saudi Arabia
}

Received 30 December 2020

Accepted 3 November 2021

\begin{abstract}
.
BACKGROUND: The coronavirus disease (COVID-19) has emerged as a global pandemic recognized by the World Health Organization. It has a significant impact on Saudi Arabia's educational process, resulting in several universities suspending on-campus teaching, exams, and training.

OBJECTIVE: The study aimed to evaluate the effect of COVID-19 on dental students' examination, internship placement, and subsequent impact on preparedness and confidence.

METHODS: A cross-sectional study was conducted to gather data from dental interns in Saudi Arabia using a pre-tested online questionnaire. Convenient sampling was applied to collect data from 5th September to 15th September 2020. Data were analyzed using SPSS version 23. Descriptive data were presented as frequency and percentages. The Chi-square test was used to evaluate the relationship between variables.

RESULTS: Data of 409 dental interns from 8 dental schools reported that $209(51 \%)$ participants' exams were affected as the format was changed to online examination. $130(31.8 \%)$ dental interns strongly agreed that assistance in hospitals during the outbreak of COVID-19 would complement their learning opportunities. Whereas $115(28.1 \%)$ respondents strongly agreed that dental schools' measures to modify their curriculum were necessary.

The impact of COVID-19 on dental intern preparedness discovered that the affected exams had a significant effect on final year students' readiness to begin the internship $(p=0.042)$. Considering students' confidence in starting the training earlier than expected, the student course had a statistically significant impact on their confidence $(p=0.002)$.

CONCLUSION: The current study demonstrates that COVID-19 had disrupted dental interns' preparedness towards clinical rotation and decreased their confidence performing in the clinical setup. Due to being unprepared and having low confidence, most dental interns were not ready to start working in the hospital on time.
\end{abstract}

Keywords: COVID-19, preparedness, confidence, dental education

\footnotetext{
*Address for correspondence: Muhammad Atif Saleem Agwan, Assistant Professor, Department of Restorative Dentistry, College of Dentistry in Ar Rass, Qassim University, Alshunanah Street, 52719, Ar Rass, Qassim, Kingdom of Saudi Arabia. E-mail: dratif agwan@yahoo.com; ORCID: 0000-0001-7019-6465.
}

\footnotetext{
${ }^{1}$ ORCID: 0000-0002-5357-3967.

${ }^{2}$ ORCID: 0000-0002-1686-9224.

${ }^{3}$ ORCID: 0000-0002-2421-0753.

${ }^{4}$ ORCID: 0000-0002-8167-6189.
} 


\section{Introduction}

Coronavirus Disease 2019 (COVID-19) is a fatal respiratory infection triggered by a novel coronavirus (SARS-CoV-2). The World Health Organization (WHO) acknowledged the disease as a pandemic on March 12, 2020 [1].

SARS-CoV-2 is a highly communicable disease and is considered to be two times more severe than seasonal flu $[2,3]$. The highly contagious nature of this virus has resulted in an exceptional response from the health authorities of the kingdom of Saudi Arabia as it has imposed social distancing at both individual and community levels. Closure of all educational institutes from schools to universities, enforcing a curfew in several parts of the kingdom [4]. Banning all types of social gatherings and public events [5]. Huge penalties have been imposed on violators. These measures were taken to reduce the spread of COVID-19 to high-risk populations such as the elderly, medically compromised individuals, and children to reduce the mortality rate $[6,7]$.

In the middle of April, the United Nations Educational and Scientific Organisation (UNESCO) announced that 192 nations closed down their universities and schools, affecting over $90 \%$ of learners worldwide, nearly affecting 1.6 billion young adults and children [8]. As a consequence of the COVID-19 pandemic, health care professional education around the globe has experienced a significant structural transition [9]. Presently, the cases of COVID-19 are tremendously increasing across the world. It is noteworthy that the collective efforts of public, government, and health care professionals can taper the condition. which is indeed occurring in some countries [10].

The existence and accelerated spread of COVID19 impose significant pressure on health care systems and economies. During such chaos, the emphasis has been on how to control the pandemic of COVID19. Steps taken to slow down the transmission of the deadly virus have disrupted health education. Due to the strange behavior of the virus, new information about COVID-19 is always needed. The existence of information gaps and the need to increase the knowledge of health care professionals and dental students are always required [11]. Students may contract the disease during training and may transmit the virus even though they are asymptomatic. Therefore, educational facilities have been shut down for the protection of healthcare students and communities [12-14]. Social distance interventions prohibit students from entering learning laboratories, classrooms, or small-group rooms [15].

Due to the closing of schools, experimental research and clinical studies are impaired. Core and elective clinical postings for students have been postponed or overdue, which has eventually delayed the assessments and educational process [16].

The initial response to the pandemic was to switch teaching and assessment online. E-learning education use increases during the COVID-19 pandemic; however, its impact on students is still unknown [17]. Medical schools in developing countries have been prepared well for this challenge because they have invested in learning management systems. By using this system, institutes were able to conduct a flipped classroom with recorded lectures. They find it easier to transfer basic science content online [10]. Schools have also suspended clinical posts for many reasons, such as restricting students' exposure to the virus, social distances, and a lack of standard precautions. Schools have begun to transfer their clinical and communication skills online by using virtual patients [18].

Assessment is another considerable concern at the time when on-site classes were suspended. The opportunity to take online tests is incorporated into different learning management systems. Still, on the other hand, a great deal of emphasis has been paid to dealing with the problems of using unfair means during online tests [16].

The effect of COVID-19 on medical education has been acknowledged both in public and private dental schools. This circumstance has prompted health educators to think and act innovatively as this pandemic has transformed the world of medical education in this particular situation.

To the best of our knowledge, no such study has been conducted in Saudi Arabia. This study would offer useful insights into dental schools about the effect of the pandemic on dental interns and future recommendations.

This study aimed to evaluate the effect of the COVID-19 pandemic on dental students' examination, internship placement, and subsequent influence on preparedness and confidence.

\section{Material and methods}

This cross-sectional study was formulated to collect data from dental interns working in different dental schools in Saudi Arabia. The data was collected from 5 to 15 September 2020 using an online 
questionnaire distributed among participants to collect information about the impact of COVID-19 on their educational and clinical rotations. All dental students from $1^{\text {st }}$ to 5 th-year dentistry were excluded from this study. A non-probability convenient sampling technique was used for data collection. The sample size was calculated by using Epi info software [19] assuming the prevalence of 50\% with a 5\% margin of error and a 95\% confidence level; a minimal sample size of 377 was required for this study. The study was approved by Qassim University Ethical Review Board (ERB) number DRC/0017FA/20.

The questionnaire used in this survey was originally in English. The authors translated the questions into Arabic and converted them into English again to ensure that the translation retained the original English version meaning.

\subsection{Data collection procedure}

An online survey was developed and distributed among dental interns working in different regions of Saudi Arabia. Before proceeding with the questions, online informed consent was obtained. A 10-item questionnaire in English and Arabic was structured to incorporate multiple-answers, dichotomous, and Likert scale questions. In addition, participants were able to submit additional free-text answers to each question.

Before the questionnaire was sent out, a focus group was developed with clinical teaching fellows to demonstrate the transition process from student to doctor that may be influenced by the COVID-19 pandemic. This approach further facilitated the survey design according to our needs and ensured that the questions were organized, clear, and coherent. The questionnaire used in this study was valid and reliable [20].

On 5th September 2020, a formulated google form was circulated among dental interns. The survey was distributed using emails and social media groups on WhatsApp, Twitter, and telegram. Responses to the questionnaire included three main results, the interns' preparation for theory examinations, clinical rotations, and their confidence when asked to help in the hospital earlier than expected.

\subsection{Data analysis}

SPSS version 23 was used for data analysis. The qualitative data were presented as frequency and percentage. Chi-square was used to determine the

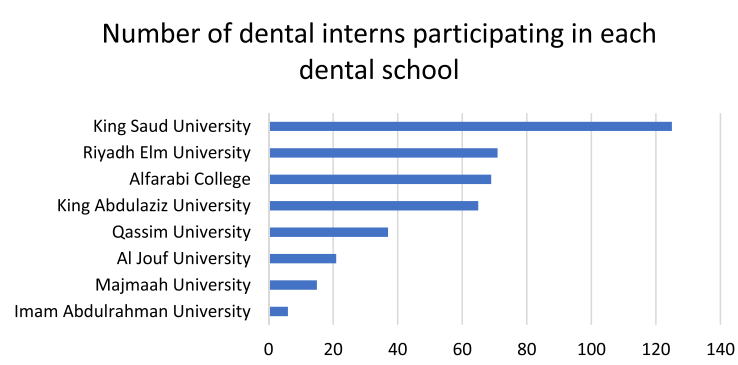

Fig. 1. List of respondents in each dental school.

relationship between variables of interest. A significant difference was recorded as $p<0.05$.

\section{Results}

Amongst the 409 dental interns aged between 18-30 years, 265 (64.8\%) were males, and 144 (35.2\%) were females, responded to the survey link from 8 dental schools in Saudi Arabia. Figure 1 shows the number of responses from each dental school. The results reveal the impact of COVID-19 on dental interns who were in the final year of the dental program during the pandemic. Concerning exam affected, 209 (51\%) reported that their exam format was changed to complete online examination while the remaining 200 (49\%) of interns responded that exams were postponed. The internship training was also affected, with $172(42 \%)$ reported that it was cancelled. Around 119 (29\%) reported postponed, 118 (29\%) reported that their format was changed.

A large number of interns, 300 (73\%), reported a change of format in student courses at their dental school. About 96 (24\%) reported that it was postponed and only $13(3 \%)$ responded that it was cancelled.

The respondents were also evaluated using 5point Likert scales for four items. 120 (29.3\%) strongly agreed, 135 (33\%) agreed, and $126(30.8 \%)$ remained neutral that they were confident to work earlier than expected in the hospital. When asked whether assisting in hospitals during the outbreak of COVID-19 would complement their learning opportunities, only 130 (31.8\%) of the participants strongly agreed whereas, $133(32.5 \%)$ agreed, while 137 $(33.5 \%)$ were found neutral. When asked whether the participants felt less prepared for internships because of the disruption caused by COVID-19, 117 (28.6\%) Agreed, 91 (22.2\%) remained neutral, 102 (24.9\%) disagreed, and 99 (24.2\%) strongly 


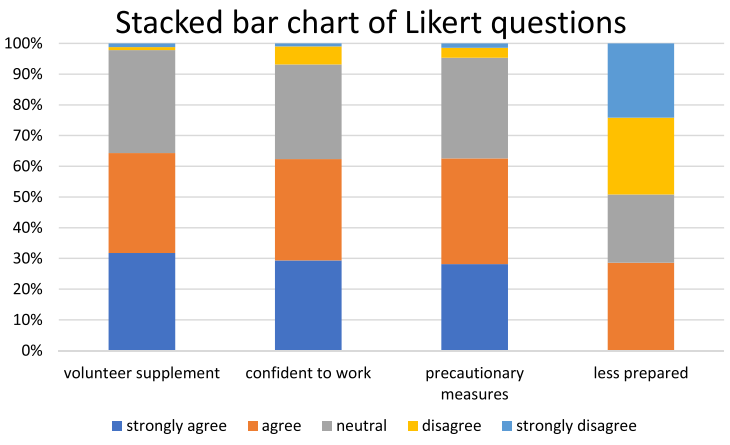

Fig. 2. Stacked bar chart with Likert questions.

disagreed. Concerning decisions made by dental schools to amend their curriculum were necessary, $115(28.1 \%)$ strongly agreed, 141 (34.5\%) agreed, and $134(32.8 \%)$ remained neutral Fig. 2.

The stacked bar chart displays four bars illustrating how dental interns responded to the Likert questions in this survey. These questions were assessed from left to right: whether interns felt less prepared for these changes; whether interns thought that it was appropriate to take precautions because of COVID19; whether interns would be confident in assisting hospitals earlier than anticipated; whether assisting in hospitals earlier than expected supplement interns learning.

The level of confidence and preparedness was analyzed to evaluate the impact of exams and internship training. The Chi-square test was used to assess the difference in our variable of interest. Considering preparedness, the affected exams significantly affected final year students to start the internship $(p=0.042)$. However, internship training did not significantly affect preparedness $(p=0.977)$ Table 1 . When evaluating students' confidence in starting the internship earlier than expected, the student course had a statistically significant effect on students' confidence $(p=0.002)$. In contrast, internship training did not significantly impact confidence $(p=0.331)$ Table 2 .

\section{Discussion}

COVID-19 has affected dental education throughout the world. A dream of every dental student is to enter into a successful residency. COVID-19 has caused a massive concern over disturbing routines in hospital care centers, medical schools, and beyond. While dentistry is known as one of the most exposed and high-risk professions, dental care professionals/students are at even greater risk [21] Various problems are currently being faced, such as remote learning, social distancing at preclinical simulation laboratories, inability to use models online, lack of programs to access the skills/expertise of students without examinations, and timely graduation. During COVID-19, European dental academic institutions have stopped clinical activity in different private and

Table 1

Factors affecting preparedness for internship

\begin{tabular}{|c|c|c|c|c|c|}
\hline Preparedness & Agree $n(\%)$ & Neutral $n(\%)$ & Disagree $n(\%)$ & Strongly disagree $n(\%)$ & $p$-value \\
\hline \multicolumn{6}{|c|}{ How has COVID-19 affected exams at your dental college? } \\
\hline Cancelled & $4(30.8 \%)$ & $4(30.8 \%)$ & $4(30.8 \%)$ & $0(0.0 \%)$ & 0.042 \\
\hline Format changed & $96(32.0 \%)$ & $64(21.3 \%)$ & $65(21.7 \%)$ & $75(25.0 \%)$ & \\
\hline Postponed & $17(17.7 \%)$ & $23(24.0 \%)$ & $33(34.4 \%)$ & $23(24.0 \%)$ & \\
\hline \multicolumn{6}{|c|}{ How has COVID-19 affected dental internship training at your dental college? } \\
\hline Cancelled & $50(29.1 \%)$ & $42(24.4 \%)$ & $41(23.8 \%)$ & $39(22.7 \%)$ & 0.977 \\
\hline Format changed & $33(28.0 \%)$ & $25(21.2 \%)$ & $31(26.3 \%)$ & $29(24.6 \%)$ & \\
\hline Postponed & $34(28.6 \%)$ & $24(20.2 \%)$ & $30(25.2 \%)$ & $31(26.1 \%)$ & \\
\hline
\end{tabular}

Table 2

Factors affecting confidence to assist in hospital earlier

\begin{tabular}{|c|c|c|c|c|c|c|}
\hline Confidence & Strongly agree $n(\%)$ & Agree $n(\%)$ & Neutral $n(\%)$ & Disagree $n(\%)$ & \multicolumn{2}{|c|}{ Strongly disagree $n(\%$} \\
\hline \multicolumn{7}{|c|}{ How has COVID-19 affected student course at your dental college? } \\
\hline Cancelled & $1(7.7 \%)$ & $12(92.3 \%)$ & $0(0 \%)$ & $0(0 \%)$ & $0(0 \%)$ & 0.002 \\
\hline Format changed & $92(30.7 \%)$ & $86(28.7 \%)$ & $100(33.3 \%)$ & $19(6.3 \%)$ & $3(1.0 \%)$ & \\
\hline Postponed & $27(28.1 \%)$ & $37(38.5 \%)$ & $26(27.1 \%)$ & $5(5.2 \%)$ & $1(1.0 \%)$ & \\
\hline \multicolumn{7}{|c|}{ How has COVID-19 affected dental internship training at your dental college? } \\
\hline Cancelled & $47(27.3 \%)$ & $54(31.4 \%)$ & $58(33.7 \%)$ & $12(7.0 \%)$ & $1(0.6 \%)$ & 0.331 \\
\hline Format changed & $41(34.7 \%)$ & $36(30.5 \%)$ & $36(30.5 \%)$ & $5(4.2 \%)$ & $0(0 \%)$ & \\
\hline Postponed & $32(26.9 \%)$ & $45(37.8 \%)$ & $32(26.9 \%)$ & $7(5.9 \%)$ & $3(2.5 \%)$ & \\
\hline
\end{tabular}


public sectors, with non-clinical teaching using live streams, pedagogical software, online meetings, connections to other interactive resources, and social media groups [22] The surgical training was greatly affected by this pandemic due to this curriculum is being reformed, and learners are motivated to access the video libraries and online multimedia resources for better understanding [23, 24] Several countries allowed only urgent or emergency surgical procedures to perform which are supported by government, societies, and regulators guidelines $[25,26]$ The influence of COVID-19 has begun to impact other aspects of student career and life. Panic is noticeable in society, and many are unsure how to proceed once the pandemic is over [27].

The current study describes the effect of COVID19 on internship placement at different dental schools around Saudi Arabia. Data of 409 dental interns from 8 dental schools were evaluated from other Saudi cities. Whether to continue internship on-site or by using virtual online patients, from March to June 2020, the actions taken by different health institutes were based on the need of pandemic. In this study, $29 \%$ of interns reported a change in the format of their training program. In another study reported that almost $68 \%$ of residents had modifications in their training program. These findings were not surprising as most dental procedures were suspended due to the risk of aerosol generation [28].

Our study reports that $31.8 \%$ of the students agreed that clinical assistance would supplement their learning during the pandemic. Gishen et al. suggested that the medical students can provide additional staffing at different clinical setups during the pandemic. They can be of immense use to the hospital and overcome workforce shortages. This will increase their own clinical experience and would make them able to handle pandemics under supervision [29].

Supervised simulation makes students practice in a stressful environment. Still, it equally decreases the fear of failure with live patients, resulting in boosting a student's confidence level and increasing competency. The pandemic caused medical education to go online halting on-site supervised mannequin practices affecting students' confidence levels. Our study reports that $29.60 \%$ of the interns did not feel confident starting in a hospital earlier than expected. These findings are in line with an investigation by Choi et al., who demonstrated that medical students felt less prepared and confident about starting to work in hospitals earlier than expected. They reported that around $59.3 \%$ of students felt less prepared, while approximately $22.7 \%$ felt less confident to start working in a hospital [20].

Almost all the educational institutes, including medical and dental schools, were closed due to the pandemic. Still, medical education was not entirely suspended because of the availability of various online platforms. Virtual communicating platforms like Zoom, Microsoft Teams, Skype, etc., have continued education using e-lectures and small group teachings. In many ways, online software has provided a way to continue educational activities despite the disturbances caused by COVID-19. In this study, $51 \%$ of the interns reported that their classes were switched to e-lectures, while $49 \%$ reported that exams were postponed. Online education and assessment have their own challenges; the reliability of online exams, network connectivity issues, barriers to avail online facilities, and determining whether the students are eligible to be promoted to the next step of training or graduation are to name a few [30].

The internship aims to encourage the transition from student to doctor and guide them with everyday tasks that they will ultimately carry on as doctors [31] A study by Bugis et al. reported that medical interns were frustrated when their internships were suspended, but they understood the effect of COVID19 on health organizations. Their study showed that almost 96 percent of medical interns who continued their on-site internships were pleased to do so. Approximately $29.4 \%$ were pleased that their internships were not discontinued, and an equivalent number were disappointed that their experience may not be as pleasing (29.41\%) [32] Their findings might support the current study, where interns reported shifting to virtual classes equally, affecting their clinical experiences and confidence levels. In the present study, a large number of interns, 73\%, reported that the teaching format had been changed regarding online/virtual internship because of the COVID-19 pandemic.

As the medical students and faculty are adapting to the challenges during the pandemic. Therefore, it is of immense importance to address all the dimensions of medical education, and its impact on medical students' career continuation, personal health, and safety [33] Teaching online presents different challenges; therefore, higher education institutions around the globe must provide standard and equal training for their faculty members to raise the bar of students' learning during the COVID-19 pandemic [34].

This study has some limitations; the sample size was not large enough to reflect the dental intern 
population during COVID-19 in Saudi Arabia; however, it has impacted a significant association of some of the findings. Moreover, the study participants belong to different regions of Saudi Arabia, representing the geographical reinforcement. The limitation mentioned earlier refers to the need to study a larger sample size in other countries.

\subsection{Future directions}

Alternative models of clinical education for dental interns should be adopted and discussed at the national level to better optimize the transition from student to doctor. Proper guidelines should be developed for online educational development for dental students during crises and future pandemics. Online evaluation systems should be properly used in medical schools across the world. The health and safety of medical students must not be jeopardized to supplement the health workforce. The focus of dental students should be to ensure that they achieve all the learning objectives needed to obtain a graduation degree with set standards.

\section{Conclusion}

The impact of COVID-19 on dental interns was significant in the Kingdom of Saudi Arabia. Most of the classes were shifted to e-lectures, which disrupted the students' preparedness towards clinical rotations and decreased their confidence to perform well in a clinical setup. Due to being unprepared and having low confidence, most of the study interns were not ready to start working in the hospital on time. The current pandemic has enforced many changes, providing a key opportunity to develop alternative modes of dental education and evaluation. Many lessons are to be learned from the pandemic, and educationists should act immediately to curtail the teaching and learning crises in medical education.

\section{Acknowledgment}

The authors would like to thank all dental interns for their participation in this study.

\section{Author contributions}

SFM and SAS conceived and designed the study. SFM, ASA, and SAS wrote the manuscript, drafted the article, and revised it critically for important con- tent. ZAS, SAS, and SA performed the data collection and curation. SFM, ASA, and SAS analyzed the data and edited the manuscript. All authors revised and approved the final version.

\section{Conflict of interest}

None to report.

\section{Funding}

None to report.

\section{References}

[1] OMS. WHO Director-General's opening remarks at the media briefing on COVID-19 - 11 March 2020. WHO Director General's Speeches 2020;4.

[2] Biggerstaff M, Cauchemez S, Reed C, et al. Estimates of the reproduction number for seasonal, pandemic, and zoonotic influenza: A systematic review of the literature. BMC Infectious Diseases 2014;14:1-20.

[3] Liu Y, Gayle AA, Wilder-Smith A, et al. The reproductive number of COVID-19 is higher compared to SARS coronavirus. Journal of Travel Medicine; 27. Epub ahead of print March 1, 2020. DOI: 10.1093/jtm/taaa021.

[4] Meo SA, Abukhalaf AA, Alomar AA, et al. Covid-19 pandemic: Impact of quarantine on medical students' mental wellbeing and learning behaviors. Pakistan Journal of Medical Sciences 2020;36:S43-S48.

[5] Ahmed QA, Memish ZA. The cancellation of mass gatherings (MGs)? Decision making in the time of COVID-19. Travel Medicine and Infectious Disease 2020;34:101631.

[6] Fernanda Carrillo-Vega MI, Salinas-Escudero G, GarcíaPeña C, et al. Early estimation of the risk factors for hospitalization and mortality by COVID-19 in Mexico. PLOS ONE 2020;15:e0238905.

[7] Karlamangla S. What's the coronavirus risk for a healthy young person? Los Angeles Times, https://www. latimes.com/california/story/2020-03-11/covid-19-risk-he althy-young-person (2020, accessed June 5, 2021).

[8] Psacharopoulos G, Patrinos H, Collis V, et al. The COVID19 cost of school closures. Brookings 2020;1-4.

[9] Goh P-S, Sandars J. A vision of the use of technology in medical education after the COVID-19 pandemic. MedEdPublish; 9. Epub ahead of print March 26, 2020. DOI: 10.15694/mep.2020.000049.1.

[10] Shrivastava D, Alduraywish AA, Srivastava KC, et al. Assessment of knowledge and attitude of allied healthcare professionals about COVID-19 across Saudi Arabia. Work 2021;68:305-315.

[11] Zandian H, Sarailoo M, Dargahi S, et al. Evaluation of knowledge and health behavior of University of Medical Sciences students about the prevention of COVID-19. Work 2021;68:543-549.

[12] Rose S. Medical Student Education in the Time of COVID19. JAMA - Journal of the American Medical Association 2020;323:2131-2132. 
[13] Ahmed H, Allaf M, Elghazaly H. COVID-19 and medical education. The Lancet Infectious Diseases 2020;20:777778.

[14] Sandhu P, de Wolf M. The impact of COVID-19 on the undergraduate medical curriculum. Medical Education Online; 25. Epub ahead of print January 1, 2020. DOI: 10.1080/10872981.2020.1764740.

[15] Del Rio C, Malani PN. 2019 Novel Coronavirus - Important Information for Clinicians. JAMA - Journal of the American Medical Association 2020;323:1039-1040.

[16] Mitra S, Gofman M. Towards Greater Integrity in Online Exams Submission Type : Emergent Research Forum Papers. 2016.

[17] Abbasi MS, Ahmed N, Sajjad B, et al. E-Learning perception and satisfaction among health sciences students amid the COVID-19 pandemic. Work 2020;67:549-556.

[18] Sudhir M, Mascarenhas S, Isaac J, et al. Adapting to the need of the hour: Communication skills simulation session using an online platform during COVID-19. MedEdPublish; 9. Epub ahead of print May 1, 2020. DOI: 10.15694/mep.2020.000085.1.

[19] Epi Info ${ }^{\text {TM }}$ | CDC, https://www.cdc.gov/epiinfo/index.html (accessed June 5, 2021).

[20] Choi B, Jegatheeswaran L, Minocha A, et al. The impact of the COVID-19 pandemic on final year medical students in the United Kingdom: A national survey. BMC Medical Education 2020;20:1-11.

[21] Banaee S, Claiborne DM, Akpinar-Elci M. Occupational health practices among dental care professionals before and during the COVID-19 pandemic. Work 2021;68:993-1000.

[22] Iyer P, Aziz K, Ojcius DM. Impact of COVID-19 on dental education in the United States. Journal of Dental Education 2020;84:718-722.

[23] Potts JR. Residency and Fellowship Program Accreditation: Effects of the Novel Coronavirus (COVID-19) Pandemic. Journal of the American College of Surgeons 2020;230:1094-1097.
[24] Teton ZE, Freedman RS, Tomlinson SB, et al. The Neurosurgical Atlas: Advancing neurosurgical education in the digital age. Neurosurgical Focus; 48. Epub ahead of print March 1, 2020. DOI: 10.3171/2019.12.FOCUS19820.

[25] Chick RC, Clifton GT, Peace KM, et al. Using Technology to Maintain the Education of Residents During the COVID-19 Pandemic. Journal of Surgical Education 2020;77:729-732.

[26] Moszkowicz D, Duboc H, Dubertret C, et al. Daily medical education for confined students during coronavirus disease 2019 pandemic: A simple videoconference solution. Clinical Anatomy 2020;33:927-928.

[27] UK Foundation Programme Office. 2 Year Foundation Programme, https://foundationprogramme.nhs.uk/pro grammes/2-year-foundation-programme/ (2018, accessed June 5, 2021).

[28] Huntley RE, Ludwig DC, Dillon JK. Early Effects of COVID-19 on Oral and Maxillofacial Surgery Residency Training - Results From a National Survey. Journal of Oral and Maxillofacial Surgery 2020;78:1257-1267.

[29] Gishen F, Gill D, Bennett S. Covid-19-the impact on our medical students will be far-reaching. BMJ: British Medical Journal.

[30] Walsh K. Point of view: Online assessment in medical education- current trends and future directions. Malawi Medical Journal 2015;27:71-72.

[31] Iacobucci G. Covid-19: medical schools are urged to fast-track final year students. BMJ (Clinical research ed) 2020;368:m1064.

[32] Bugis BA. COVID-19 and Internship Opportunities at Health Organizations in Saudi Arabia. The Open Public Health Journal 2021;13:779-782.

[33] O NF. SARS and its effect on medical education in Hong Kong. Medical Education. 2003;37:1127-1128.

[34] Sarfaraz S, Ahmed N, Abbasi MS, et al. Self-perceived competency of the medical faculty for E-Teaching during the COVID-19 pandemic. Work 2020;67:791-798. 